\title{
Do Blood Cell Parameters have a Predictive Role in the Etiology and Severity Pediatric Antrochoanal Polyp Cases?
}

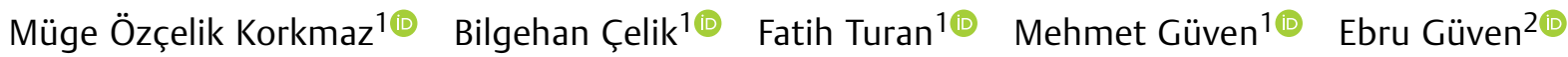 \\ ${ }^{1}$ Department of Otolaryngology, Sakarya University Medical Faculty, \\ Korucuk, Sakarya, Turkey \\ 2 Sakarya Hizirtepe Family Medical Center, Serdivan, Sakarya, Turkey \\ Address for correspondence Müge Özçelik Korkmaz, MD, Altinişik \\ Cad. Defne Evler Sitesi.No:36/B2 Serdivan, Sakarya, 54440, Turkey \\ (e-mail: ozcelikmuge@gmail.com).
}

Int Arch Otorhinolaryngol 2021;25(2):e229-e234.

\begin{abstract}
Introduction There are no definitive parameters to guide the etiology and severity of pediatric antrochoanal polyps.

Objective The aim of our study is to compare the values of blood cell distribution parameters in cases of pediatric antrochoanal polyps (ACPs) with those of the control group. These values may be guiding parameters in determining the etiology of ACPs and evaluating the severity of the disease and the risk of recurrence.

Methods Blood count values of patients operated for pediatric ACPs were retrospectively analyzed and compared with the data of the control group with the same age and gender distribution. The ACPs group was divided into subgroups in terms of inflammation, severity, and recurrence, and these subgroups were statistically compared as well. Results When the ACP patient group and the control group were compared, there was no statistically significant difference between the two groups. When we compared

Keywords

- antrochoanal polyp

- pediatric

- neutrophil-tolymphocyte ratio

- blood cell

- paranasal sinus tomography the patients considering the $\mathrm{CT}$ findings, there was a statistically significant difference between the stage III patients and the control group in terms of mean platelet volume (MPV) and platelet-to-lymphocyte ratio (PLR) values ( $p<0.05$ in both). Similarly, the MPV and PLR values were significantly higher in the recurrence patient group than in the control group. ( $p<0.05$ in both).

Conclusion As a result of the data obtained, it can be suggested that inflammatory parameters in pediatric cases of ACPs vary in terms of recurrence and the severity of the disease.
\end{abstract}

\section{Introduction}

Antrochoanal polyps (ACPs) are benign solitary inflammatory polyps arising from the maxillary sinus mucosa and extending from the maxillary sinus ostium to the choanal opening. These lesions, which were first described by Killian in 1906, do not cause destruction of the surrounding soft

received

November 6, 2019

accepted

February 17, 2020

published online

June 23, 2020
DOI https://doi.org/ 10.1055/s-0040-1709194. ISSN 1809-9777. tissue and bone. ${ }^{1,2}$ Although a few rare bilateral cases have been reported in the literature, ACPs almost always show up unilaterally. ${ }^{3}$ Nasal obstruction and nasal discharge are the most common presenting symptoms, although in rare cases, the presentation could be severe with dyspnea and/or obstructive sleep apnea, dysphagia or epistaxis. ${ }^{4}$ They represent $\sim 4$ to $6 \%$ of all nasal polyps in the general population. ${ }^{2,4}$ (c) 2020. Fundação Otorrinolaringologia. All rights reserved.

This is an open access article published by Thieme under the terms of the Creative Commons Attribution-NonDerivative-NonCommercial-License, permitting copying and reproduction so long as the original work is given appropriate credit. Contents may not be used for commercial purposes, or adapted, remixed, transformed or built upon. (https://creativecommons.org/ licenses/by-nc-nd/4.0/)

Thieme Revinter Publicações Ltda., Rua do Matoso 170, Rio de Janeiro, RJ, CEP 20270-135, Brazil 
In the pediatric population, this rate appears to be closer to $33 \%$ of all nasal polyps. ${ }^{5}$

Although some theories, such as chronic infection, lymphatic obstruction, and epithelial rupture theory, have been proposed regarding the development of ACPs, no definitive pathophysiological cause could be determined yet. ${ }^{6,7}$ The developmental etiology of ACPs is much different from that of nasal polyposis. In addition, there are no definitive findings to explain the higher incidence of ACPs, especially in the pediatric age group. However, a study comparing the clinical findings in cases of pediatric and adult ACPs showed that the disease severity was higher in the pediatric than in the adult group, according to computed tomography (CT) findings. ${ }^{8}$

Recently, there are studies in the literature showing that hemogram parameters are associated with the severity of the disease and recurrence in chronic inflammatory diseases. ${ }^{9,10}$ Especially, the parameters correlated with the severity of systemic inflammation, such as the neutrophil-to-lymphocyte ratio (NLR) and the platelet-tolymphocyte ratio (PLR), have also been shown to increase in cases of nasal polyposis. ${ }^{11}$ Moreover, there are also studies suggesting that these parameters may be considered as an indicator for recurrence in cases of nasal polyposis. ${ }^{12}$ Furthermore, in cases of obstructive pathology, it is suggested that especially mean platelet volume (MPV) and PLR ratios show an alteration in children and adults, and this is also a risk factor for possible cardiovascular complications. ${ }^{13,14}$ Based on these studies, we considered that the hemogram parameters could vary in cases of pediatric ACPs due to the severity of inflammation and nasal obstruction.

The aim of our study was to compare the blood count parameters and NLR, PLR, and MPV related to chronic inflammation in cases of pediatric ACPs with those of the control group. Besides that, we planned to investigate whether these values vary in terms of etiology, severity, and recurrence characteristics of the disease.

\section{Patients and Methods}

The research protocol was submitted to and approved by the ethics committee of the Sakarya University Medical Faculty and was conducted in accordance with the ethical regulations of the Declaration of Helsinki and in adherence to the laws and regulations. The approval number of the ethics committee was 71522473/050.01.04/122. The records of patients aged between 6 and 17 years, who were operated with unilateral polyp etiology in the Sakarya University otolaryngology clinic between January 2009 and January 2019, were retrospectively evaluated for our study. A total of 68 patients whose operative and pathological findings were consistent with ACPs were included in the study group. A total of 60 children with the same age range and gender distribution were determined as the control group. Patients with systemic diseases, such as uncontrolled diabetes mellitus, allergic rhinitis, asthma, active connective tissue disease, vasculitis, inflammatory bowel disease, chronic kidney failure, and chronic liver failure, were excluded from the study. The age, gender, paranasal sinus tomography findings, pathological data, operation notes, and recurrence information of the patients were evaluated and recorded.

Peripheral venous blood samples taken before the operation were studied on a Cell-Dyn 3700 SL device (Abbott Diagnostics, Abbott Park, IL, USA), and neutrophil, lymphocyte, platelet and eosinophil counts as well as red blood cell distribution width (RDW), platelet distribution width (PDW), and MPV values were recorded. Using this data, the neutrophil, platelet and eosinophil counts were divided by the lymphocyte, RDW, MPV, and PDW counts, so the NLR, PLR, and eosinophil-to-lymphocyte ratio (ELR) values were calculated. The obtained data were compared with the control group.

We classified the patients based on preoperative paranasal sinus computed tomography (PNS CT) findings: stage I (antronasal polyp), stage II (ACP extended to the nasopharynx and the ostium of the maxillary sinus was occluded fully by the neck of the ACP), and stage III (ACP extended to the nasopharynx and the ostium of the maxillary sinus was occluded partially by the neck of the ACP). ${ }^{15}$

The blood cell distribution parameters of the patients in the study were compared to those of the control group. In addition, the patients in the study group were divided into subgroups according to the presence of recurrence and CT findings, and the same data were compared between these subgroups.

\section{The Statistical Analysis}

The statistical analysis was performed using the IBM SPSS version 24.0 for Windows statistical software (IBM Corporation, Armonk, NY, USA). The continuous variables were expressed as mean \pm standard deviation and median, and the categorical variables were expressed as percentage. The Kolmogorov-Smirnov and Shapiro-Wilk tests were performed for normality distribution analyses. We used oneway analysis of variance (ANOVA) to compare multiple groups of normally distributed variables. For the subgroup comparisons, we used Tukey's multiple comparison test and Dunn's multiple comparison test. For the comparison of nonnormally distributed variables, we used the MannWhitney $U$ tests. The Chi-squared test was used for the comparison of the categorical variables. $P$-values of $<0.05$ were accepted as significant.

Table 1 Demographic data of patients

\begin{tabular}{|c|c|l|l|l|l|}
\hline \multirow{2}{*}{ Variables } & \multicolumn{2}{|l|}{ Study group } & \multicolumn{2}{l|}{ Control group } & \multirow{2}{*}{$\boldsymbol{p}$} \\
\cline { 2 - 5 } & $\mathbf{n}$ & $\begin{array}{l}\text { Mean } \pm \text { SD } \\
\text { (age) }\end{array}$ & $\mathbf{n}$ & $\begin{array}{l}\text { Mean } \pm \text { SD } \\
\text { (age) }\end{array}$ & \\
\hline Gender & & & & & 0.65 \\
\hline Female & 33 & $10.8 \pm 2.97$ & 28 & $10.28 \pm 4.23$ & 0.57 \\
\hline Male & 30 & $13.23 \pm 3.65$ & 32 & $12.9 \pm 2.41$ & 0.57 \\
\hline Total & 63 & $12.18 \pm 2.97$ & 60 & $11.36 \pm 2.43$ & 0.68 \\
\hline
\end{tabular}

Abbreviation: SD, standard deviation. 

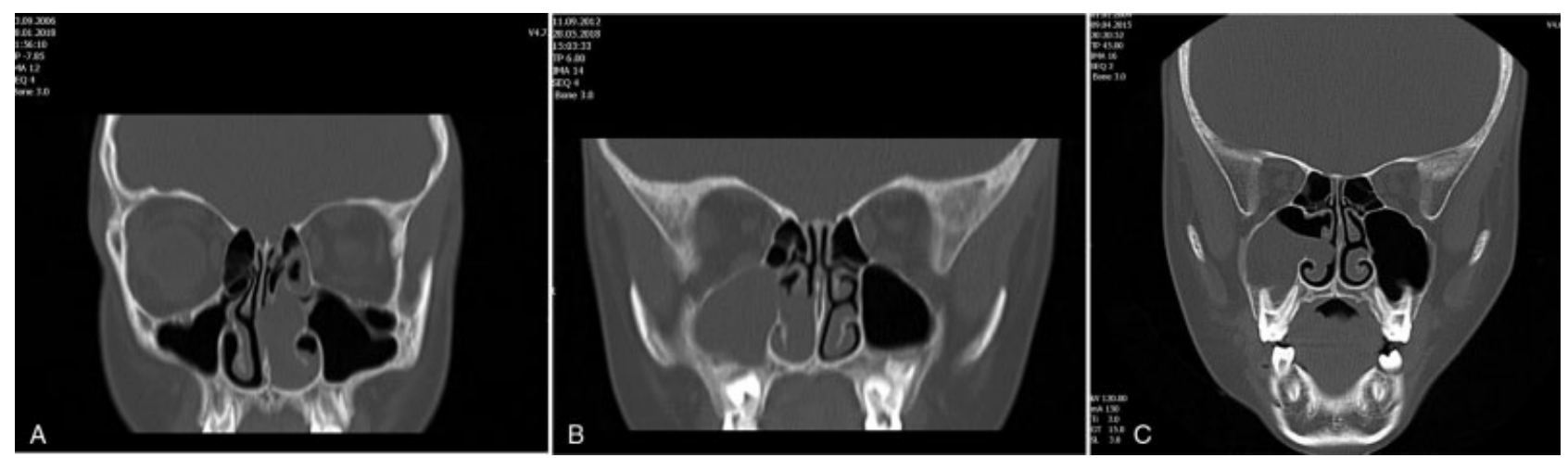

Fig. $1(a-c)$ Coronal cross-sectional images of patients with stage 1, 2 and 3, respectively, on paranasal sinus tomography.

\section{Results}

\section{Patients' Data}

Of the patients in the study group, 33 (52.38\%) were female and 30 (47.62\%) were male. Of the patients in the control group, 28 patients were female and 32 were male. The mean age of the patients in the study group was $12.18 \pm 2.97$ years ( $\min 6$-max 17 ), while the mean age in the control group was $10.36 \pm 3.67$ years (min 6-max 17). There was no statistically significant difference between the two groups in terms of age and gender distribution $(p=0.05, p>0.05)$.( - Table 1$)$ When the operation notes and histopathology records of the cases in the study group were evaluated, it was found that unilateral endoscopic sinus surgery along with uncinectomy + polyp excision was performed in 61 cases, and the Caldwell-Luc operation was added in 2 cases. The ACP was located on the right side in 33 (52.38\%) of the cases and on the left side in 30 (47.62\%) of the cases. The median follow-up period of the cases was $40.26 \pm 3.57$ months ( $\min 6-\max 120$ ), and 18 (26.47\%) of the cases had recurrence developed. All histopathological data were reported as chronic inflammatory polyp.
When the patients in the study group were classified by the preoperative PNS CT findings, 25 patients (39.68\%) were evaluated as stage III, 12 patients (19.04\%) as stage I, and 26 (41.26\%) patients as stage II. (-Fig. 1a-c)

\section{Blood Cell Parameters}

There was no statistically significant difference between the study and control groups in terms of neutrophil, lymphocyte, platelet, eosinophil, basophile, RDW, PDW and MPV counts. Likewise, there was no statistically significant difference in terms of NLR, PLR, and ELR values. (- Table 2)

When the recurrence patients $(n=18,28,57 \%)$ and nonrecurrence patients $(n=45 ; 71.42 \%)$ in the study group were evaluated between themselves, the neutrophil and PLR values of the recurrence patients were significantly higher than those of the non-recurrence patients $(p=0.021 ; p=0.032)$. ( - Table 3 ) Additionally, the MPV and PLR values of the patients in the stage III group, according to preoperative CT findings, were significantly higher than those of the control group $(p=0.022$, $p=0.037$ ). There was no statistically significant difference

Table 2 Comparison of study and control groups in terms of blood cell parameters

\begin{tabular}{|l|l|l|l|}
\hline \multirow{2}{*}{ Parameters } & Study group $(\boldsymbol{n}=\mathbf{6 8})$ & Control group $(\boldsymbol{n}=\mathbf{6 0})$ & $\boldsymbol{p}^{*}$ \\
\cline { 2 - 4 } & Mean \pm SD & Mean \pm SD & 0.797 \\
\hline Neutrophil & $4,034 \pm 1,175.14$ & $3,967.63 \pm 1,506, .23$ & 0.120 \\
\hline Lymphocyte & $2,608.54 \pm 893.03$ & $2,884.72 \pm 954.68$ & 0.935 \\
\hline Platelet & $2,897.09 \pm 45.53$ & $2,904.90 \pm 54.52$ & 0.395 \\
\hline Eosinophil & $196.38 \pm 156.57$ & $222.23 \pm 160.6$ & 0.513 \\
\hline Basophil & $0.09 \pm 0.23$ & $0.076 \pm 0.12$ & 0.791 \\
\hline RDW & $15.70 \pm 1.32$ & $15.64 \pm 1.02$ & 0.393 \\
\hline PDW & $17.42 \pm 0.87$ & $17.26 \pm 1.07$ & 0.107 \\
\hline MPV & $7.38 \pm 0.90$ & $7.1 \pm 0.9$ & 0.284 \\
\hline NLR & $1.74 \pm 0.81$ & $1.56 \pm 0.89$ & 0.056 \\
\hline PLR & $126.47 \pm 58.95$ & $109.41 \pm 35.07$ & 0.784 \\
\hline ELR & $0.07 \pm 0.06$ & $0.08 \pm 0.06$ & \\
\hline
\end{tabular}

Abbreviations: ELR, eosinophil-to-lymphocyte ratio; MPV, mean platelet volume; NLR, neutrophil-to-lymphocyte ratio; PDW, platelet distribution width; PLR, platelet-to-lymphocyte ratio; RDW, red blood cell distribution width; SD, standard deviation. 
Table 3 Comparison of blood cell parameters between in recurrence and non-recurrence patients groups

\begin{tabular}{|l|l|l|l|}
\hline \multirow{2}{*}{ Parameters } & Recurrent group $(\boldsymbol{n}=\mathbf{1 8})$ & Non-recurrent group $(\boldsymbol{n}=\mathbf{4 5})$ & \multirow{2}{*}{$\boldsymbol{N}$} \\
\cline { 2 - 3 } & Mean \pm SD & Mean \pm SD & 0.021 \\
\hline Neutrophil & $4,567.64 \pm 1,229.26$ & $3,778.91 \pm 1,093.06$ & 0.963 \\
\hline Lymphocyte & $2,359.41 \pm 785.79$ & $2,643,24 \pm 955.96$ & 0.867 \\
\hline Platelet & $290,294.11 \pm 376.41$ & $280,918.91 \pm 489.73$ & 0.449 \\
\hline Eosinophil & $208,4595 \pm 179.15$ & $173.0 \pm 97.19$ & 0.867 \\
\hline Basophil & $0.087 \pm 0.23$ & $0.096 \pm 0.12$ & 0.834 \\
\hline RDW & $15.61 \pm 1$ & $15.7 \pm 1.45$ & 0.408 \\
\hline PDW & $17.58 \pm 1.07$ & $17.37 \pm 0.77$ & 0.190 \\
\hline MPV & $7.46 \pm 0.83$ & $7.34 \pm 0.95$ & 0.169 \\
\hline NLR & $1.96 \pm 0.84$ & $1.63 \pm 0.8$ & 0.032 \\
\hline PLR & $123.05 \pm 71.49$ & $106.28 \pm 54.1$ & 0.853 \\
\hline ELR & $0.07 \pm 0.06$ & $0.08 \pm 0.07$ & 0.96 \\
\hline
\end{tabular}

Abbreviations: ELR, eosinophil-to-lymphocyte ratio; MPV, mean platelet volume; NLR, neutrophil-to-lymphocyte ratio; PDW, platelet distribution width; PLR, platelet-to-lymphocyte ratio; RDW, red blood cell distribution width; SD, standard deviation.

Table 4 Comparison of blood cell parameters in terms of computed tomography findings grading of patients and control group

\begin{tabular}{|l|l|l|l|l|l|}
\hline \multirow{2}{*}{ Parameters } & Stage I group $(\boldsymbol{n}=\mathbf{1 2})$ & $\begin{array}{l}\text { Stage II } \\
(\boldsymbol{n}=\mathbf{2 6})\end{array}$ & $\begin{array}{l}\text { Stage III } \\
(\boldsymbol{n}=\mathbf{2 5})\end{array}$ & $\begin{array}{l}\text { Control } \\
(\boldsymbol{n}=\mathbf{4 5})\end{array}$ \\
\cline { 2 - 5 } & Mean \pm SD & Mean \pm SD & Mean \pm SD & Mean \pm SD \\
\hline Neutrophil & $4,088.88 \pm 1,041.32$ & $4,489.18 \pm 1,283.61$ & $3,983.75 \pm 911.48$ & $3,967.63 \pm 1,506.23$ & 0.865 \\
\hline Lymphocyte & $2,494.44 \pm 795.17$ & $2,733.78 \pm 931.54$ & $2,213.75 \pm 812.56$ & $2,871.78 \pm 950.91$ & 0.232 \\
\hline Platelet & $298,555.55 \pm 5,269.67$ & $290,027.02 \pm 4,241.78$ & $2,851.25 \pm 5,498.44$ & $2,895.00 \pm 5,429.39$ & 0.857 \\
\hline Eosinophil & $216.11 \pm 165 ., 11$ & $196.89 \pm 163.38$ & $178 \pm 139.38$ & $220.89 \pm 159.45$ & 0.449 \\
\hline Basophil & $0.097 \pm 0.23$ & $0.086 \pm 0.12$ & $0.089 \pm 0.23$ & $0.095 \pm 0.12$ & 0.867 \\
\hline RDW & $15.65 \pm 0.95$ & $15.70 \pm 1.43$ & $15.56 \pm 1.23$ & $15.67 \pm 1.04$ & 0.834 \\
\hline PDW & $17.3 \pm 0.52$ & $17.35 \pm 0.82$ & $17.97 \pm 1.29$ & $17.26 \pm 1.06$ & 0.408 \\
\hline MPV & $7.26 \pm 0.89$ & $7.42 \pm 0.93$ & $8.31 \pm 0.94$ & $7.10 \pm 0.89$ & 0.022 \\
\hline NLR & $1.73 \pm 0.56$ & $1.69 \pm 0.85$ & $1.94 \pm 0.95$ & $1.65 \pm 0.85$ & 0.675 \\
\hline PLR & $128.36 \pm 44.74$ & $122.08 \pm 60.89$ & $149.86 \pm 69.47$ & $109.4 \pm 34.75$ \\
\hline ELR & $0.09 \pm 0.08$ & $0.07 \pm 0.06$ & $0.07 \pm 0.05$ & $0.08 \pm 0.06$ & 0.037 \\
\hline
\end{tabular}

Abbreviations: ELR, eosinophil-to-lymphocyte ratio; MPV, mean platelet volume; NLR, neutrophil-to-lymphocyte ratio; PDW, platelet distribution width; PLR, platelet-to-lymphocyte ratio; RDW, red blood cell distribution width; SD, standard deviation.

between the other groups and the control group $(p=0.067$, $p=0.062$ ). ( - Table 4)

\section{Discussion}

Antrochoanal polyps are solitary polyps arising within the maxillary sinus and extending to the nasopharynx through the posterior nasal cavity. ${ }^{4}$ It has been suggested that the polyp arises from the blocked and ruptured acinous mucous glands during the healing process of sinusitis, thus being an extension of a mucocele. ${ }^{7}$ Various theories have been proposed in terms of the causes inducing the development of ACP. In the literature, there are studies revealing the role of arachidonic acid metabolites, urokinase-type plasminogen activator and plasminogen activator inhibitor-110, cytokine and IL-6 in the etiopathogenesis. ${ }^{16-18}$ Mostofa et al suggested the lymphatic obstruction theory, and they found increased lymphatic density in the transitional area between the sinus mucosa and the ACP pedicle. ${ }^{7}$ However, one of the best known points about ACP is that it is more common in children and young adolescents. ${ }^{1,4}$ The reasons for the more frequent incidence of ACP in childhood have not been clarified yet. However, chronic sinusitis and allergy are the most commonly emphasized topics on this topic. In the studies on pediatric patients, the incidence of ACPs in children with chronic sinusitis has been reported as 20.7\%. ${ }^{19}$ Both Cook et al and Heck et al reported allergy in a considerable percentage of their patients with ACPs $(23.4 \%$ and $69.7 \%$, respectively). They found a statistically significant 
correlation between ACPs and allergies. ${ }^{5,6}$ On the other hand, other researchers failed to find even one case of a wellconfirmed allergic basis among patients with ACP. ${ }^{20}$ Considering the literature, it is seen that several blood parameters, such as total eosinophil, basophil count or ELR in cases of pediatric allergic rhinitis, provide data supporting allergy. ${ }^{21,22}$ Although there are not many studies evaluating blood parameters in cases of pediatric ACP from this point of view, the study by Pagella et al found no significant difference in terms of eosinophil and basophil values. ${ }^{23}$ In this study, there was also no significant difference between ACP cases and the control group in terms of preoperative eosinophil and basophil values. Similarly, there was no significant difference between the two groups in terms of ELR value ( $p>0.05$ for both).

Recently, new inflammatory biomarkers, including MPV, RDW, NLR, and PLR values observed in complete blood count (CBC) testing, have been used to detect systemic inflammation levels in the human body. These notably include NLR, and it was also seen that PLR and ELR counts have been investigated in various studies. Although there are many studies on their correlations with disease severity and recurrence in nasal polyposis cases, it is noted that the two most commonly associated values in this respect are ELR and NLR. ${ }^{11,24}$ The studies showed that PLR was more valuable than NLR in chronic inflammation, and it has been emphasized that PLR is an important inflammation marker., ${ }^{9,25}$ Furthermore, there are also studies suggesting that PLR is a predictive marker in nasal polyposis cases. ${ }^{12}$ Considering that another topic in ACP etiology is chronic sinusitis and inflammation, there may be changes in the inflammatory blood parameters of these patients. In our study, there was no statistically significant difference between the pediatric ACP cases and the control group in terms of the specified parameters $(p>0.05)$. In our study, we evaluated the patients according to recurrence and severity of infection, as in the studies on nasal polyposis. In our study, the recurrence rate of ACP was $26.47 \%$. In a study on recurrence rates in pediatric cases, the mean recurrence rate was reported to be $15 \% .{ }^{26}$ However, in the study by Lee et al on comparison of pediatric and adult ACP cases, the rate of recurrence was found to be higher in adults. ${ }^{8}$ Although the rate of recurrence was higher than the average rate in our study, it should be kept in mind that the recurrence rates may vary in the pediatric age group. When the patients in our study were grouped in terms of recurrence development, it was found that the PLR and MPV values were higher in the recurrence group $(p<0.05)$. Although the small number is statistically a question mark, considering the similar studies on nasal polyposis in this respect, it is seen that there are similar patient ratios between recurrence and non-recurrence cases. ${ }^{11,24}$

Furthermore, when we classified the patients in the study group according to the preoperative CT findings in terms of the severity of infection, it was found that the majority of the patients ( $n=31.65 \%)$ were stage II. Accordingly, the MPV and PLR values were higher in 25 patients whose findings were interpreted as stage III $(p<0.05)$. This was thought to be due to obstructive pathology caused by the extension of the current polyp to the nasopharynx. In a study by Pagella et al, it was reported that in pediatric ACP cases, the incidence of nasal obstruction as a symptom was 93\% and the rate of obstructive sleep apnea syndrome (OSAS) was $40 \%{ }^{23}$ In the literature, there are studies showing that obstructive pathologies alter blood parameters in pediatric cases. In the study by Erdim et al on obese children with sleep apnea disorder, it was found that the NLR, PLR, and RDW values were significantly higher in the group with a apnea-hypopnea index $(\mathrm{AHI}) \geq 5$ than in the control group. ${ }^{13}$ In the study conducted by Kucur et al, 105 patients with adenoid hypertrophy and 100 age- and sexmatched healthy people were compared. The MPV levels were significantly higher in patients with adenoid hypertrophy. When the pre and postoperative MPV levels of the study group were compared, it was found that there was a significant decrease in the MPV levels of the postoperative group. ${ }^{27}$ In the studies, it is seen that the MPV and PLR values are mostly associated with increased cardiovascular risk. Although the preoperative AHI of our patients in the study group was not evaluated, the high MPV and PLR values in the stage III group may be important in terms of indicating that the cardiovascular risks associated with potential obstruction may increase in ACP cases.

Although the data obtained from a recent study will not change the treatment strategy of ACPs, we think that these findings will be helpful to understand the etiology and effects of ACP in the pediatric age group. Especially knowing that recurrent rhinological infections may play a role in the development of ACP may be useful for patient follow-up.

\section{Conclusion}

Pediatric ACPs account for the majority of childhood polyps. Although there are different theories in the literature about the etiology of ACP, the theories proposed are allergy and chronic sinusitis. There are studies suggesting that especially NLR and PLR values may be the determinant parameters in terms of severity of inflammation and recurrence in cases of nasal polyposis. Furthermore, there are publications reporting that the ELR and PLR values increase in allergic individuals. However, in our study conducted on pediatric ACP cases, there was no significant difference in the blood parameters of the patients with ACP compared with those of the control group. However, when the patients were grouped as recurrence and non-recurrence, according to the infection severity in the preoperative CT findings, the MPV and PLR values of the stage III patients with recurrence were significantly higher than those of the control group. We are of the opinion that this will contribute to the etiology and potential effects of the disease in pediatric ACP cases. More comprehensive controlled studies to be conducted in the future will provide more detailed data on this issue.

\section{Ethical Standards}

All procedures performed in the present study involving human participants were in accordance with the ethical standards of national research committee and with the 
1964 Helsinki declaration and its later amendments or comparable ethical standards.

\section{Informed Consent}

Informed consent was obtained from all participants included in the present study.

\section{Conflict of Interests}

The authors declare that have no conflict of interests.

\section{Acknowledgments}

The authors have no acknowledgments to disclose for this article.

\section{References}

1 Killian G. The origin of choanalpolypi. Lancet 1906;2:81-82

2 Yaman H, Yilmaz S, Karali E, Guclu E, Ozturk O. Evaluation and management of antrochoanal polyps. Clin Exp Otorhinolaryngol 2010;3(02):110-114

3 Myatt HM, Cabrera M. Bilateral antrochonanal polyps in a child: a case report. J Laryngol Otol 1996;110(03):272-274

4 Maldonado M, Martínez A, Alobid I, Mullol J. The antrochoanal polyp. Rhinology 2004;42(04):178-182

5 Cook PR, Davis WE, McDonald R, McKinsey JP. Antrochoanal polyposis: a review of 33 cases. Ear Nose Throat J 1993;72:404-410

6 Heck WE, Hallberg OE, Williams HL. Antrochoanal polyp. AMA Arch Otolaryngol 1950;52(04):538-548

7 Mostafa HS, Fawzy TO, Jabri WR, Ayad E. Lymphatic obstruction: a novel etiologic factor in the formation of antrochoanal polyps. Ann Otol Rhinol Laryngol 2014;123(06):381-386

8 Lee DH, Yoon TM, Lee JK, Lim SC. Difference of antrochoanal polyp between children and adults. Int J Pediatr Otorhinolaryngol 2016; 84:143-146

9 Nacaroglu HT, Erdem SB, Karaman S, Yazici S, Can D. Can mean platelet volume and neutrophil-to-lymphocyte ratio be biomarkers of acute exacerbation of bronchiectasis in children? Cent Eur J Immunol 2017;42(04):358-362

10 Klinger MH, Jelkmann W. Role of blood platelets in infection and inflammation. J Interferon Cytokine Res 2002;22(09): 913-922

11 Kara A, Guven M, Yilmaz MS, Demir D, Elden H. Are neutrophil, platelet and eosinophil-to-lymphocyte ratio and red blood cell distribution width can be used for nasal polyposis? Eur Arch Otorhinolaryngol 2018;275(02):409-413
12 Boztepe OF, Gün T, Demir M, Gür ÖE, Ozel D, Doğru H. A novel predictive marker for the recurrence of nasal polyposis following endoscopic sinus surgery. Eur Arch Otorhinolaryngol 2016;273 (06):1439-1444

13 Erdim I, Erdur O, Oghan F, Mete F, Celik M. Blood count values and ratios for predicting sleep apnea in obese children. Int J Pediatr Otorhinolaryngol 2017;98:85-90

14 Koseoglu HI, Altunkas F, Kanbay A, Doruk S, Etikan I, Demir O. Platelet-lymphocyte ratio is an independent predictor for cardiovascular disease in obstructive sleep apnea syndrome. J Thromb Thrombolysis 2015;39(02):179-185

15 Chung SK, Chang BC, Dhong HJ. Surgical, radiologic, and histologic findings of the antrochoanal polyp. Am J Rhinol 2002;16(02):71-76

16 Ozcan C, Unal M, Görür K, Pata YS OzcanC. [A review of antrochoanal polyps in 14 cases]. Kulak Burun Bogaz Ihtis Derg 2002;9 (03):188-192

17 Aktaş D, Yetisser S, Gerek M, Kurnaz A, Can C, Kahramanyol M. Antrochoanal polyps: analysis of 16 cases. Rhinology 1998;36 (02):81-85

18 Min YG, Chung JW, Shin JS, Chi JG. Histologic structure of antrochoanal polyps. Acta Otolaryngol 1995;115(04):543-547

19 Ozcan M, Ozlugedik S, Ikinciogullari A. Simultaneous antrochoanal and sphenochoanal polyps: a rare clinical entity. J Laryngol Otol 2005;119(02):152-154

20 Frosini P, Picarella G, De Campora E. Antrochoanal polyp: analysis of 200 cases. Acta Otorhinolaryngol Ital 2009;29(01):21-26

21 Yenigun A, Sezen S, Calim OF, Ozturan O. Evaluation of the eosinophil-to-lymphocyte ratio in pediatric patients with allergic rhinitis. Am J Rhinol Allergy 2016;30(02):e21-e25

22 Amato GM, Amato G, Barcellona R, et al. [Diagnosis in pediatric "allergic" patients]. Minerva Pediatr 1997;49(11):521-528

23 Pagella F, Emanuelli E, Pusateri A, et al. Clinical features and management of antrochoanal polyps in children: Cues from a clinical series of 58 patients. Int J Pediatr Otorhinolaryngol 2018;114:87-91

24 Brescia G, Pedruzzi B, Barion U, et al. Are neutrophil-, eosinophil-, and basophil-to-lymphocyte ratios useful markers for pinpointing patients at higher risk of recurrent sinonasal polyps? Am J Otolaryngol 2016;37(04):339-345

25 Turkmen K. Platelet-to-Lymphocyte Ratio: One of the novel and valuable platelet indices in hemodialysis patients. Hemodial Int 2013;17(04):670-673

26 Galluzzi F, Pignataro L, Maddalone M, Garavello W. Recurrences of surgery for antrochoanal polyps in children: A systematic review. Int J Pediatr Otorhinolaryngol 2018;106:26-30

27 Kucur C, Kulekci S, Zorlu A, Savran B, Oghan F, Yildirim N. Mean platelet volume levels in children with adenoid hypertrophy. J Craniofac Surg 2014;25(01):e29-e31 